\title{
Motivaçóes para a experiência transicional das estudantes do curso de especializaçáa em enfermagem
}

\author{
Motivations for the transitional experience of students in the nursing \\ specialization degree \\ Motivaciones para la experiencia de transición de las estudiantes \\ de especialización en enfermería
}

Rosana Maria de Oliveira Silva ${ }^{1}$

iD https://orcid.org/0000-0003-3371-6550

Josicelia Dumêt Fernandes ${ }^{1}$

(iD) https://orcid.org/0000-0003-2946-5314

Maria Deolinda Antunes Luz Lopes Dias

Maurício $^{2}$

(iD) https://orcid.org/0000-0002-6565-1694

Lázaro Souza da Silva ${ }^{1}$

(iD) https://orcid.org/0000-0003-1841-751X

Gilberto Tadeu Reis da Silva ${ }^{1}$

(iD) https://orcid.org/0000-0002-0595-0780

Ana Lúcia Arcanjo Oliveira Cordeiro

(iD) https://orcid.org/0000-0002-0375-7709

${ }^{1}$ Universidade Federal da Bahia, Salvador, Bahia, Brasil

${ }^{2}$ Escola Superior de Enfermagem de Lisboa, Lisboa, Portugal

Autor de correspondência

Rosana Maria de Oliveira Silva

E-mail: rosanaosilva@hotmail.com

Recebido: 10.02.20

Aceite: 02.11 .20

\section{Resumo}

Enquadramento: A experiência transicional de especialistas de enfermagem ocorre por meio de mudanças intencionais motivadas pela possibilidade de qualificar o exercício profissional.

Objetivo: Analisar as motivaçóes para a experiência transicional das egressas do curso de especialização em enfermagem de um município do Nordeste do Brasil.

Metodologia: Estudo transversal e exploratório realizado com 40 enfermeiras egressas do curso de especialização em enfermagem na modalidade de residência. Para a colheita dos dados foi utilizada a técnica de entrevista semiestruturada com roteiro norteador. Os dados obtidos foram analisados à luz da análise de conteúdo.

Resultados: $\mathrm{O}$ estudo possibilitou a construção da categoria motivaçóes para a experiência transicional, que discute as motivaçóes para a experiência transicional, o que resultou em três subcategorias temáticas - necessidade de aprofundar o conhecimento e vivenciar a prática; insuficiência da graduação; e experiência prévia em cenários de prática.

Conclusáo: A realização do curso de especialização é uma experiência transicional motivada pelas possibilidades de qualificar o exercício profissional de enfermeiras.

Palavras-chave: educação de pós-graduação em enfermagem; especialização; enfermagem

\section{Abstract}

Background: The transitional experience of nurse residents occurs through intentional changes motivated by the possibility of enhancing their practice.

Objective: To analyze the motivations for the transitional experience of former students of the nurse residency program in a municipality in Northeast Brazil.

Methodology: Cross-sectional exploratory study carried out with 40 former students of the nurse residency program. The semi-structured interview technique with a guide was used for data collection. Data were analyzed through content analysis.

Results: The category Motivations for the transitional experience emerged, which discusses the motivators influencing the transitional experience. Three subcategories also emerged: Need to enhance knowledge and experience clinical practice; Undergraduate training is insufficient; and Previous experience in practical settings.

Conclusion: The completion of the nurse residency program is a transitional experience motivated by the possibilities of improving nurses' practice.

Keywords: education, nursing, graduate; specialization; nursing

Resumen

Marco contextual: La experiencia de transición de las residentes de enfermería se produce a través de cambios intencionales motivados por la posibilidad de cualificarse en su ejercicio profesional.

Objetivo: Analizar las motivaciones de la experiencia de transición de las estudiantes de especialización en enfermería en un municipio del noreste de Brasil.

Metodología: Estudio transversal y exploratorio realizado con 40 enfermeras de los estudios de especialización en enfermería, en la modalidad de residencia. Para recopilar los datos se utilizó la técnica de la entrevista semiestructurada con guion dirigido según el análisis de contenido.

Resultados: El estudio hizo posible la construcción de la categoría "motivaciones de la experiencia de transición", en la que se examinan las motivaciones de la experiencia de transición, lo que dio lugar a tres subcategorías temáticas, necesidad de profundizar en el conocimiento y experimentar la práctica; la insuficiencia de la graduación, y la experiencia previa en los escenarios de la práctica.

Conclusión: La realización de los estudios de especialización es una experiencia de transición motivada por las posibilidades de las enfermeras para cualificarse en su ejercicio profesional.

Palabras clave: educación de posgrado en enfermería; especialización; enfermería

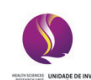
Escola Superior de
Enfermagem de 0 imbra
Como citar este artigo: Silva, R. M., Fernandes, J. D., Maurício, M. D., Silva, L. S., Silva, G. T., \& Cordeiro, A. L. (2020). Motivaçốes para a experiência transicional das estudantes do curso de especialização em enfermagem.. Revista de Enfermagem Referência, 5(3), e20021. doi:10.12707/RV20021 


\section{Introdução}

O curso de especialização em enfermagem, é desenvolvido por meio da parceria entre a universidade e os serviços de saúde, é a experiência de pós-graduação projetada para desenvolver competências e conhecimento inerentes à prática de enfermagem, numa determinada área de atuação, visto que, possibilita às enfermeiras a vivência no quotidiano do trabalho em saúde (Cline, La Frentz, Fellman, Summers, \& Brassil, 2017; Oliveira et al., 2017). Atualmente, existem, em todo o Brasil, um total de 973 cursos de especialização para enfermeiras em 273 programas, o que revela a importância destes cursos para a qualificação de enfermeiras e das práticas assistenciais no Sistema Único de Saúde.

A experiência transicional vivenciada por estas profissionais nos espaços da prestaçáo do cuidado, na procura por saberes e desenvolvimento de competências, é processual e evidenciada ao longo do processo de formação.

O curso proporciona um aprofundamento do conhecimento técnico/científico, permite o desenvolvimento de conhecimento e de segurança para a realização das técnicas assistenciais, da prestação de assistência de forma integral e humanizada. Permite ainda o desenvolvimento do raciocínio clínico e da capacitação do profissional para a tomada de decisão, possibilitando crescimento e, por conseguinte, levando a melhores condiçóes de trabalho e maior inserção no mercado de trabalho (Showalter et al., 2017; Silva, Cordeiro, Fernandes, Silva, \& Teixeira, 2014) ao possibilitar o desenvolvimento de marketing pessoal e profissional. Os cursos de especialização foram projetados prioritariamente para a capacitação de enfermeiras recém graduadas, no sentido de promover com sucesso a transição para enfermeiras especialistas, tornando-as competentes e confiantes no seu papel como profissionais (Scherzer, Dennis, Swan, Kavuru, \& Oxman, 2017).

Neste sentido, o estudo de Cline et al. (2017) mostra que os recém graduados procuram estes cursos para obterem as competências necessárias para o desenvolvimento de uma assistência qualificada, desenvolverem confiança na execução das suas tarefas como profissionais e para uma maior inserção no mercado de trabalho.

No entanto, observa-se a existência de outras motivaçóes que impulsionam o profissional a planear ingressar num curso de especializaçáo, os quais passamos a citar: expectativas relativamente ao aumento do salário, à ocupação de um melhor cargo no trabalho, à valorização curricular e à possibilidade de ampliar a rede de relaçóes com pessoas que tem a mesma afinidade/área de atuação. Destacam-se também, as influências das mudanças do contexto político e social do país. Neste sentido, o aumento do número de vagas no curso de graduação em enfermagem, aliado ao crescente desemprego nesta categoria profissional, parece influenciar na elevada procura por uma vaga nesta modalidade de curso, assim como o financiamento de bolsas para os estudantes de especialização e a possibilidade de inserçáo imediata no mercado de trabalho.

Baseado nestas consideraçóes, investigar quais são as motivações para a experiência transicional das egressas do curso de especialização em enfermagem justifica-se, principalmente, pela possibilidade dos seus resultados fornecerem conhecimento científico para a compreensão do contexto e para nortear o desenvolvimento de ações que promovam a ampliação de vagas e criação de novos programas. Estas açôes visam responder às necessidades das enfermeiras e melhorar a estruturação dos cursos de especialização.

Frente ao exposto, definiu-se como objetivo deste estudo analisar as motivaçóes para a experiência transicional das egressas do curso de especialização em enfermagem de um município do Nordeste do Brasil.

\section{Enquadramento}

A experiência transicional significa a mudança ocorrida entre dois períodos impassíveis, direcionando o indivíduo a mover-se por diferentes etapas dinâmicas, marcos e pontos de mudança. Esta transição é complexa e multidimensional e apresenta propriedades como consciencialização, comprometimento, mudança e diferença, intervalo de tempo, pontos e eventos críticos. Estudos na literatura de enfermagem, referentes à transição, resultaram na organizaçấo de quatro tipos de transiçáo: desenvolvimental, saúde-doença, organizacional e situacional (Meleis, 2017). Neste sentido, as motivações para a experiência transicional, vivenciada por enfermeiras ao realizar o curso de especialização, são permeadas por mudanças advindas de uma experiência transicional situacional, partindo do pressuposto que a mesma foi intencional e planeada (Meleis, 2017).

Quanto à tipificação intencional da experiência transicional, a decisão de procurar e trilhar um caminho e viver uma experiência transicional no curso de especializaçáo, pretende promover mudanças na situação ou na realidade vivenciada, para outra que melhor responda às inquietaçôes quanto à profissão e ao ser enfermeira (Meleis, 2017; Silva et al., 2017).

Ao visar a experiência da transição situacional, é necessário planear a vida pessoal e profissional, o que leva à conclusão de que esta transiçáo possa ser, ainda, adjetivada de transição planeada. A experiência transicional tem origem em motivaçóes que possam gerar mudanças, o que, neste estudo, foi a realizaçáo do curso de especialização em enfermagem.

O curso de especialização em enfermagem, é um curso de especializaçáo, caracterizado pela imersão direta do profissional na assistência ao utente visto que dá a oportunidade às enfermeiras de vivenciarem o quotidiano do trabalho em saúde, além do aprofundamento teórico/ científico no processo do cuidar (Oliveira et al., 2017). Sabe-se que a enfermeira mobiliza competências profissionais específicas, durante a realização do seu trabalho, procurando aliar conhecimento técnicocientífico, domínio da tecnologia, humanização, e, consequentemente, qualidade na assistência prestada. Acompanhar a complexidade dos sistemas de saúde requer a atualização contínua para a transformação da prática e desenvolvimento de competências que a auxiliem na 
dinâmica do seu processo de trabalho, nomeadamente na capacidade para enfrentar possíveis desafios (Leal, Soares, Silva, Bernardes, \& Camelo, 2018).

As competências profissionais do enfermeiro abrangem açóes para: identificar as necessidades em saúde da população; formular e processar problemas de saúde; elaborar, executar e avaliar a implementaçáo do plano de cuidados e monitorizar os seus desfechos, garantir a continuidade da atenção à saúde, assim como, participar na organizaçáo e no acompanhamento do processo de trabalho em saúde (Leal et al., 2018).

\section{Questão de Investigação}

Quais são as motivaçóes para a experiência transicional das egressas do curso de especialização em enfermagem de um município do Nordeste do Brasil?

\section{Metodologia}

Trata-se de um estudo transversal, descritivo-exploratório, fundamentado na Teoria de Transição de Médio Alcance de Afaf Meleis que enfatiza a importância do conceito e do processo de transição e as implicações para a prática da Enfermagem na promoção, prevenção e intervenção, e para o aumento do conhecimento específico da ciência da enfermagem (Meleis, 2017).

As participantes deste estudo foram 40 enfermeiras especialistas do curso de especialização em enfermagem, que atenderam aos critérios de inclusão: morar no estado da Bahia e estar a concluir o curso no período de 1996 a 2009. Como critérios de exclusão: participantes que se encontravam de férias ou de licença durante o período de recolha de dados.

Foi utilizado o método snowball sampling (bola de neve), no qual os primeiros indivíduos selecionados foram incumbidos de indicar outros indivíduos e assim sucessivamente (Atkinson \& Flint, 2001). Foram explicados os critérios de inclusão às participantes identificadas e solicitada a indicação de outras enfermeiras especialistas dos cursos de especialização que atendessem aos critérios estabelecidos.

A colheita de dados foi realizada de janeiro a março de 2012, pela primeira autora, no desenvolvimento da pesquisa matriz "Trajetória profissional de enfermeiros egressas dos programas de residência multiprofissional em saúde e em área profissional da saúde do estado da Bahia", financiado pela Universidade Federal da Bahia por meio de recurso do Programa de Apoio a Jovens Doutores (PROPESQ). Foi utilizada a entrevista semiestruturada com roteiro norteador, contendo questóes que permitiram perceber as motivaçóes para a experiência transicional das egressas.

As entrevistas ocorreram dentro das unidades hospitalares onde as participantes trabalhavam, em local escolhido pelos entrevistados, evitando-se a possibilidade de interrupção por terceiros.

No momento inicial da entrevista foram explicitados os objetivos, as possíveis repercussóes do processo de investigação e garantido aos participantes o seu anonimato e o do local da entrevista. A carta convite para participação da pesquisa foi apresentada aos participantes e foi solicitado o preenchimento e a assinatura do Termo de Consentimento Livre e Esclarecido em duas vias, ficando uma para o investigador e a outra para os participantes. Para o registo da entrevista, foi solicitado o consentimento das participantes para a gravaçáo por meio de um gravador digital. Cada entrevista teve duração média de 90 minutos. Foram concluídas 94 horas e 42 min de transcrição. Nesta etapa utilizou-se o software profissional Express Scribe 5.20, para controlo do playback do áudio e consideraram-se as etapas: transcrição absoluta, textualização e conferência pelos participantes. Considerando a existência de diferenças entre o que foi narrado e o que foi escrito, foi necessário que o participante lesse o que foi transcrito e autorizasse a sua utilização.

As narrativas foram submetidas à análise de conteúdo temático, o que permitiu fazer inferências sobre as informaçôes encontradas, no contexto do qual as mesmas estavam inseridas, permitindo que a análise ultrapassasse o caráter meramente descritivo e alcançasse caráter analítico. A investigação seguiu as três etapas da análise de conteúdo: pré-análise; exploração do material; tratamento dos resultados: a inferência e a interpretação (Bardin, 2009). $\mathrm{Na}$ pré-análise o material proveniente das entrevistas foi organizado e posteriormente realizada a leitura flutuante. Na segunda etapa ou de exploração do material, foram feitas releituras de todo o conteúdo do corpus da investigaçáo, iniciando com a identificação e apreensão das unidades de contexto - frases, ou seja, parágrafos do corpus que representavam as condiçóes favoráveis e desfavoráveis da experiência transicional na trajetória das egressas do curso. A terceira e última etapa - a inferência e a interpretação, foi realizada mediante a interpretaçâo dos resultados, considerando o referencial da Teoria de Transição de Afaf Meleis.

Para preservar a identidade dos egressos, optou-se pela utilização do sistema alfanumérico por meio do codinome E., relativo à entrevistada, seguido da numeração arábica, conforme ordem de ocorrência das entrevistas (E.1, E.2, E.3... E.40).

Com o objetivo de assegurar os direitos e deveres no que diz respeito à comunidade científica, aos participantes da pesquisa e ao Estado, o estudo foi realizado segundo a Resolução 466, de 12 de dezembro de 2012, atendendo às diretrizes e normas regulamentadoras de investigaçóes que envolvem seres humanos e que englobam os princípios básicos da bioética, (Ministério da Saúde, Conselho Nacional de Saúde, 2012). O projeto foi aprovado pela Comissão de Ética e Pesquisa da Instituição de Ensino Superior (IES), sob parecer no 35/2010.

\section{Resultados}

Com base na análise das entrevistas de egressas no programa de especialização em enfermagem, foi possível identificar e analisar as motivaçóes para a experiência transicional, as quais foram dispostas em três subcategorias: 
Necessidade de aprofundar o conhecimento e vivenciar a prática, Insuficiência da graduação e Experiência prévia em cenários de prática.

\section{Necessidade de aprofundar o conhecimento e vivenciar a prática}

Nesta subcategoria as participantes relatam a necessidade de aprofundar o conhecimento e vivenciar a prática como motivos para realizarem o curso. Como pode ser exemplificado pelas falas:

"Necessidade de um conhecimento que fosse mais aprofundado pra embasar a minha prática" (E.1; janeiro de 2012).

"Era uma aluna que buscava sempre conhecimento, mas sentia que precisava de algo mais profundo, que me desse mais prática" (E.4; janeiro de 2012). Os relatos expressam a necessidade das enfermeiras em aprofundar o seu conhecimento como um dos motivos que as conduziram ao curso de especialização, caracterizado, marcantemente, pela elevada carga horária de estágio em ambientes concretos de trabalho, subsidiado por conteúdo teórico em determinada área do saber.

A decisão de fazer o curso de especialização como meio de aquisição de conhecimentos específicos foi motivada pelas possibilidades oferecidas por este curso e expectativas das enfermeiras, como forma de suprir necessidades, de experienciar vivências de práticas profissionais.

"ao procurar saber como era a proposta do curso, e o que o curso me daria, eu percebi que teria estágios" (E.4; janeiro de 2012).

O curso de especialização possibilita a associação da prática com a teoria, fomentando a construção e reconstrução destes elementos. Desta forma, as alunas adquirem conhecimentos mais sólidos para atuarem nas áreas especializadas.

\section{Insuficiência da graduação}

A insuficiência da graduação para atuar em área de especialidade foi relatada pelas entrevistadas ao destacar o pouco tempo nos campos de estágio, considerando-se o propósito de se tornarem profissionais diferenciadas. Como se pode exemplificar através das seguintes falas:

"Você termina a graduação e fica um pouco perdida porque você passa pelos campos de estágio e é tudo tão rápido, pouco tempo e poucas horas" (E.27; março de 2012).

A graduação é muito pouco, oferece pouco, o tempo é pouco, é mínimo, é preciso muito mais na nossa área, é muito mais complexo e é uma área que cresce e que muda muito e que você nunca pode parar de estudar. (E.3; janeiro de 2012)

As enfermeiras também revelaram: "A gente sai da graduação com pouco conhecimento, não é nem pouco, é um conhecimento que não é suficiente para nossa atuação" (E.3; janeiro de 2012).

"O motivo para fazer a Residência foi uma questáo pessoal, eu estava me sentindo ainda muito despreparada pro mercado" (E.6; janeiro de 2012).

\section{Experiência prévia em cenários de prática}

A experiência prévia com a área foi um dos motivos mencionados pelas enfermeiras egressas para realizarem o curso de especialização. É possível verificar através das seguintes declarações:

"Na graduação eu fiz um período de estágio numa UTI, foi uma coisa que me direcionou pra isso" (E.2; janeiro de 2012).

Fui pra UTI do Hospital público X e aí me encantei, fui conhecendo a vivência, a rotina da unidade, como eram os pacientes críticos, lá é trauma e fui me encantando, e aí desde entâo me apaixonei pela, pela UTI. (E.7; janeiro de 2012)

Percebe-se que as egressas despertaram para a possibilidade de realizar o curso de especialização após frequentarem estágios nas áreas afins do curso de especialização, durante a sua formaçáo inicial, de acordo com os relatos das que saíram direto da graduação para a especialização; ou a partir da experiência profissional nas áreas de cirurgia ou de terapia intensiva.

Quando eu vim fazer a seleção para a prova do curso eu já havia tido contato com a UTI em Feira de Santana. Tinha gostado e tinha me interessado pela UTI, apesar de que lá era uma semi e tinha surgido esse sentimento de fazer UTI. (E.22; março de 2012) Quando tive acesso, como bolsista do curso de especialização, ... f foi quando parei, olhei, para aqueles enfermeiros, daquele curso e olhei para os materiais que eu tinha nas mãos e disse que era isso o que eu queria fazer. Fiz a seleção. (E.15; fevereiro de 2012).

Os relatos das experiências prévias em cenários de prática são considerados modalidades de aprendizagem ao possibilitar a aprendizagem em contextos reais de trabalho, permitindo ao profissional refletir sobre o seu modo de ser e estar na profissão.

\section{Discussão}

A necessidade de aprofundar o conhecimento e vivenciar a prática foi um dos motivos que levou as enfermeiras a fazer o curso. Desta forma, na continuidade da formaçáo profissional, através de uma especialização, a enfermeira planeia transitar do perfil generalista, tendo origem na sua formaçáo e definido pelas Diretrizes Curriculares do Curso de Enfermagem, para o perfil da enfermeira especialista, o que significa imergir num processo sistematizado de aprendizagem. Frente a isto, torna-se necessário que o indivíduo procure novos conhecimentos e habilidades ao fazer uma transição de uma função para outra (Meleis, 2017).

A perceção das enfermeiras para a necessidade de aprofundar o conhecimento e vivenciar a prática demonstra o comprometimento das egressas com a formação profissional. O comprometimento é entendido como o grau de envolvimento demonstrado pelo indivíduo com a experiência transicional. $\mathrm{O}$ indivíduo só se compromete se tiver consciência da transição que está a viver. Um dos exemplos de comprometimento é a procura por informaçôes e conhecimentos (Meleis, 2017).

A formação por meio de um curso de especialização 
favorece o aprofundamento do conhecimento à medida que articula os dois campos de formação, a universidade e os serviços prestadores de assistência à saúde, que, ao se comprometerem com a formação, facultam condiçóes para que a profissional mobilize conhecimentos numa dada especialidade (Oliveira et al., 2017).

O curso de especialização, na sua conceção, parte do pressuposto de que a aprendizagem depende da vontade e capacidade da aluna para construir uma formação otimizada e em realizar-se profissionalmente. $O$ paradigma do saber é priorizado, colocando o indivíduo numa posição de sujeito da sua própria aprendizagem e corresponsável pela qualidade da sua formação.

É no processo de associar o conhecimento teórico-prático com as questóes políticas, sociais e culturais inerentes ao ser humano e aos valores ético-morais da profissão, que se deve fundamentar a formação da enfermeira especialista (Yama, Hodgins, Boydell, \& Schwartz, 2018).

Outro motivo referido pelas enfermeiras egressas foi a insuficiência da graduação já que o tempo para o desenvolvimento das práticas é insuficiente.

Ao se discutir sobre a educação da enfermagem no Brasil, uma das perspectivas para a graduação é a garantia da formação de profissionais autónomos na atenção à saúde da populaçấo, com qualidade para assegurar a integralidade da atenção à saúde e ao cuidado humanizado (Fernandes et al., 2020).

Soma-se a isto, o cenário da formação inicial das enfermeiras, as quais são protagonistas de um perfil generalista em que, como alunas precisam de conteúdos multidisciplinares, numa carga horária mínima, exigida em períodos curtos, com poucas oportunidades, nos diversos cenários de práticas, que, muitas vezes, não lhes permitem desenvolver todas as competências necessárias ao alcance de segurança para atuar, conforme comumente se observa na prática.

Estudo realizado no Brasil, com 21 profissionais de saúde que concluíram a graduação e especialização, aponta que as profissionais ao saírem da graduação ainda se senteminseguras, despreparadas e inexperientes, pelo facto de a assistência em saúde requerer habilidades para lidar com a gestão em saúde, emoções, tomadas de decisôes e conhecimentos do próprio profissional, e das pessoas, objetos da sua assistência, principalmente, nas áreas de especialidades oferecidas no programa da especializaçáo das egressas (Ramos \& Rennó, 2018).

Isto é até compreensível, dado ao facto da saída dos cursos de graduação para ingressar no mundo do trabalho ser cada vez mais competitivo. Deste modo, entende-se que a enfermeira se sinta insegura no que diz respeito à execução das suas tarefas, tornando-se vital a procura por cursos de capacitação, o que podemos dizer tratar-se de uma transição situacional.

A conscientização da transição pode ser percebida quando as egressas reconhecem, relembram a sua trajetória de graduandas para enfermeiras e percebem que a graduação forma enfermeiros generalistas. Esta consciência relacionase com a perceçáo do conhecimento e do reconhecimento de uma experiência transicional pelo indivíduo e influencia o nível de envolvimento da egressa, na transição (Meleis,
2017).

A egressa, ao ser colocada no mercado de trabalho, acaba por ser submetida a uma nova formação, a partir da sua experiência pessoal, somada à cultura e à filosofia da instituição onde é inserido. Sendo assim, a frágil relação entre formação e a prática profissional gera insegurança, medo e procura colmatar as lacunas da graduação (Jesus, Sena, Souza, Pereira, \& Santos, 2015).

Deste modo, ao competir por uma vaga no mundo do trabalho, a profissional procura um curso de especializaçáo para se diferenciar e atender aos pré-requisitos exigidos pelo mercado.

Neste momento, o curso torna-se para a profissional, muitas vezes, a única possibilidade de suprir estas necessidades e facilitar a sua inserção no mercado de trabalho, podendo ser considerado um marco para a redefinição desta profissional, principalmente com a perceção de que uma formação generalista não as habilitaria para atuar com completa destreza e conhecimento científico em qualquer área da enfermagem (Jesus et al., 2015).

Não distante desta realidade, outra motivação para a experiência transicional foi a necessidade de ter uma experiência prévia em cenários de prática já que, durante a sua formação inicial, sentiram a necessidade de realizar estágios para uma melhor preparação para a inserção do mercado de trabalho.

Em virtude das transiçóes serem processuais e ocorrerem ao longo do tempo, a menção da experiência prévia em cenários de prática, por algumas enfermeiras, é um indicador de processo de transição (Meleis, 2017). Estes são importantes, pois através deles é possível descobrir e esclarecer os comportamentos advindos da transição, que, conforme elucidado nesta categoria, a experiência prévia orientou a escolha da especialização.

A entrada no mundo do trabalho possibilita, à recémformada, a aquisiçāo de conhecimentos novos e específicos, reflexão sobre o seu desempenho profissional, além da reconstrução da identidade profissional, a perceção dos valores éticos morais, a identificação das fragilidades da sua formação, no que tange a áreas de atuação específicas, despertando, a necessidade de dar continuidade ao seu processo formativo. Deste modo, as experiências prévias influenciam as expectativas do indivíduo em relação ao resultado da vivência da experiência transicional (Meleis, 2017).

É válido ressaltar que durante a graduação as enfermeiras no processo de especialização têm uma carga horária prática e de estágio que lhes dá oportunidade para frequentar diversos cenários de prática com o objetivo de vivenciarem situaçóes reais de trabalho e se desenvolverem como ser humano e profissional.

As diretrizes Curriculares Nacionais do Curso de Enfermagem, regulamentada através da Resolução do Conselho Nacional de Educação e Câmara de Educação Superior no 3, de 07 de novembro de 2001, registam no seu artigo sétimo, a obrigatoriedade dos Cursos de Graduação incluírem nos seus projetos político pedagógicos, além do conteúdo teórico-prático, o estágio supervisionado. Este deve ser desenvolvido, nos dois últimos semestres, em organizaçôes hospitalares gerais e especializadas, redes 
básicas de saúde e em comunidades (Conselho Nacional de Edução, Câmara de Educação Superior, 2001).

Neste sentido, o processo de formação na contemporaneidade aponta, pois, para a capacitação do profissional para o exercício das competências gerais e específicas, além de habilidades pautadas nas conceçōes do aluno como sujeito do seu próprio processo de formação, da articulação entre teoria e prática e da diversificação dos cenários de aprendizagem, evidenciadas pelos estágios em diversos setores da assistência em saúde (Silva, Fernandes, Teixeira, \& Silva, 2010).

No momento em que a formação possibilita, por meio dos estágios, aprendizagem em situações reais de trabalho, permite que se efetivem as relaçôes de multi e transdisciplinaridade, identifique e vivencie o jogo de poderes, conheça a dinâmica das unidades, a estrutura organizacional e as normas ético-legais, que envolvem as relações interprofissionais e com o usuário do serviço de saúde, seja ele o cliente e/ou os seus familiares, e, permite a tomada de decisão perante imprevisível.

Neste contexto, destacam-se aqueles que estáo relacionados com a aquisição, desenvolvimento e avaliação das competências e das habilidades, dos conteúdos essenciais, das práticas e estágios, pois são exatamente essas competências que irão suprir as necessidades e os objetivos da formação do profissional (Silva et al., 2010). Deste modo, a experiência prévia em cenários de prática com a área de especialização escolhida, também deu oportunidade à aluna, de conhecer essa mesma área e de se identificar ou não com ela. De certo modo, reduzem-se as incompatibilidades, as insatisfaçóes e a aceitação de um vínculo de trabalho com uma área inconciliável com a aptidão, como profissional. Assim, a experiência prévia foi um dos estímulos externos que fizeram com que as enfermeiras fossem impelidas de frequentar o curso de especialização e, consequentemente, experienciar a transição.

Considera-se como limitação deste estudo a impossibilidade de generalizar o universo dos egressos de programas de especialização, visto que foi desenvolvido numa determinada realidade do Nordeste brasileiro. No entanto, as participantes e o contexto escolhido para este estudo podem ser considerados representativos a nível regional. Este estudo proporciona conhecimento sobre a experiência transicional de egressas dos programas de especializaçáo no estado da Bahia. Além disso, contribui para o incentivo à realização de novas investigações sobre as motivaçóes para a experiência transicional em outros espaços de ensino que desenvolvam programas de especialização.

\section{Conclusão}

A partir do presente estudo, ficou evidenciado, através da entrevista e análise temática, que as motivações para a experiência transicional das egressas do curso de especialização, são estimuladas pela experiência prévia em cenários de áreas afins do programa e pela necessidade de aprofundar o conhecimento e vivenciar a prática, por forma a suprir a insuficiência da licenciatura.

As experiências prévias em cenários de prática podem nortear as escolhas das especialidades, podendo ser consideradas como uma aprendizagem, pela possibilidade do graduando refletir sobre a forma de ser e estar na profissão, subsidiando e guiando a trajetória profissional. Aprofundar o conhecimento e vivenciar a prática é uma motivação entendida pela estrutura pedagógica do curso de especialização, conhecido tradicionalmente, pela elevada carga horária de estágio em ambientes concretos de trabalho, e pela experiência de associar a prática com a teoria, proporcionando conhecimentos mais sólidos para atuarem nas áreas especializadas.

A insuficiência de conhecimento na graduação como motivaçáo para a experiência transicional é traduzida pelo sentimento de inexperiência e insegurança, causada pela incongruência entre as expectativas das participantes, ao iniciar a sua formação com as vivenciadas quando finalizada, ou seja, quando graduada.

Importa ressaltar que as motivaçóes para a experiência transicional das estudantes de especialização favorecem o processo de transição situacional por ser intencional e planeada com vista a mudanças no âmbito profissional. Neste sentido, recomendam-se outros estudos sobre as motivaçôes dos profissionais em relação às suas escolhas e experiências, visando orientar projetos de formação profissional em cursos de especialização em enfermagem. Torna-se necessário, também, aumentar a oferta de cursos neste formato, visto que, os mesmos, atendem às expectativas de enfermeiros no desenvolvimento das competências para melhorar a qualidade do trabalho.

\section{Contribuição de autores}

Conceptualização: Silva, R. M. O., Fernandes, J. D., Maurício, M. D. A. L. L. D., Silva, L. S., Silva, G. T. R., Cordeiro, A. L. A. O.

Tratamento de dados: Silva, R. M. O.

Análise Formal: Silva, R. M. O., Fernandes, J. D., Maurício, M. D. A. L. L. D.

Metodologia: Silva, R. M. O., Fernandes, J. D., Maurício, M. D. A. L. L. D., Silva, L. S., Silva, G. T. R., Cordeiro, A. L. A. O.

Redação - preparação do rascunho original: Silva, R. M. O, Fernandes, J. D.

Redação - revisão e edição: Silva, R. M. O., Fernandes, J. D., Maurício, M. D. A. L. L. D., Silva, L. S., Silva, G. T. R., Cordeiro, A. L. A. O.

\section{Referências bibliográficas}

Atkinson, R., \& Flint, J. (2001). Accessing hidden and hard-to-reach populations: Snowball research strategies. Social Research UPDATE, 33, 1-4. Recuperado de http://sru.soc.surrey.ac.uk/SRU33.pdf

Bardin, L. (2009). Análise de conteúdo (5ª ed.). Lisboa, Portugal: Ediçóes 70.

Cline, D., La Frentz, K., Fellman, B., Summers, B., \& Brassil, K. (2017). Longitudinal outcomes of an institutionally developed nurse residency program. Journal of Nursing Administration, 47(78), 384-390. doi:10.1097/NNA.0000000000000500

Fernandes, J. D., Silva, R. M., Teixeira, G. A., Florêncio, R. M., Silva, L. S., \& Freitas, C. M. (2020). Educação em enfermagem: 
Mapeamento na perspectiva de transformação. Revista Brasileira de Enfermagem, 73(3), e20180749. doi:10.1590/0034-71672018-0749

Jesus, I. S., Sena, E. L., Souza, L. S., Pereira, L. C., \& Santos, V. T. (2015). Vivências de estudantes de graduação em enfermagem com a ansiedade. Revista Enfermagem UFPE Online, 9(1), 149-157. doi:10.5205/reuol.6817-60679-1-ED.0901201521

Leal, L. A., Soares, M. I., Silva, B. R., Bernardes, A., \& Camelo, S. H. (2018). Clinical and management skills for hospital nurses: Perspective of nursing university students. Revista Brasileira de Enfermagem, 71(sup. 4), 1514-1521. doi:10.1590/0034-71672017-0452

Meleis, A. I. (2017). Theoretical nursing: Development and progress (6th ed.). Philadelphia, PA: Wolters Kluwer Health.

Conselho Nacional de Edução, Câmara de Educação Superior. (2001). Resolução CNE/CES no 3, de 07 de novembro de 2001: Institui diretrizes curriculares nacionais do curso de graduação em enfermagem. Recuperado de http://www.cofen.gov.br/wp-content/ uploads/2012/03/resolucao_CNE_CES_3_2001Diretrizes_ Nacionais_Curso_Graduacao_Enfermagem.pdf

Ministério da Saúde, Conselho Nacional de Saúde. (2012). Resolução $n^{\circ}$ 466, de 12 de dezembro de 2012: Aprova as diretrizes e normas regulamentadoras de pesquisas envolvendo seres humanos. Recuperado de https://bvsms.saude.gov.br/bvs/saudelegis/cns/2013/ res0466_12_12_2012.html

Oliveira, E. B., Carvalho, R. A., Teixeira, E., Zeitoune, R. C., Sabóia, V. M., \& Gallasch, C. H. (2017). Factors involved in the training of resident nurses: View of alumni from a residency program. REME: Revista Mineira de Enfermagem, 21, e-1064. doi:10.5935/1415-
2762.20170074

Ramos, T. M., \& Rennó, H. M. (2018). Formaçấo na residência de enfermagem na atenção básica/saúde da família sob a ótica dos egressos. Revista Gaúcha de Enfermagem, 39, e2018-0017. doi:10.1590/1983-1447.2018.2018-0017

Scherzer, R., Dennis, M. P., Swan, B. A., Kavuru, M. S., \& Oxman, D. A. (2017). A comparison of usage and outcomes between nurse practitioner and resident-staffed medical ICUs. Critical Care Medicine, 45(2), 132-137. doi:10.1097/CCM.0000000000002055 Showalter, B. L., Cline, D., Yungclas, J., Frentz, K., Stafford, S. R., \& Maresh, K. J. (2017). Clinical research nursing development of a residency program. Clinical Journal of Oncology Nursing, 21(5), 633-636. doi:10.1188/17.CJON.633-636

Silva, M. G., Fernandes, J. D., Teixeira, G. A., \& Silva, R. M. (2010). Processo de formação da (o) enfermeira(o) na contemporaneidade: Desafios e perspectivas. Texto Contexto Enfermagem, 19(1), 176184. doi:10.1590/S0104-07072010000100021

Silva, R. M., Cordeiro, A. L., Fernandes, J. D., Silva, L. S., \& Teixeira, G. A. (2014). Contribuição do curso de especialização, modalidade residência para o saber profissional. Acta Paulista de Enfermagem, 27(4), 362-366. doi:10.1590/1982-0194201400060

Silva, R. M, Fernandes, J. D., Luz, M. D., Cordeiro, A. L., Silva, L. S., \& Silva, A. C. (2017). Concepción de la teoría de transición de Afaf Meleis posibilidades de aplicación para la enfermería. Revista ROL Enfermeria, 40(7-8), 498-503.

Yama, B. A., Hodgins, M., Boydell, R., \& Schwartz, S. B. (2018). A qualitative exploration: Questioning multisource feedback in residency education. BCM Medical Education, 18(170). doi:10.1186/s12909-018-1270-7 